\title{
Lactose Intolerance in Patients Fulfilling The Rome-III Criteria for Irritable Bowel Syndrome in a Tertiary Hospital in Bangladesh
}

\author{
Mohammad Sofiul Kadir ${ }^{1}$, Mohammed Shafiqul Islam Bhuiyan ${ }^{2}$, Md.Shahidur Rahman ${ }^{3}$, Md.Shakhawat \\ Hossain $^{4}$, Mohammad Abu Faisal ${ }^{5}$, Jannatul Ferdous Suma ${ }^{6}$, M.M. Sarowar Jahan ${ }^{7}$ \\ 1. Assistant Professor of Gastroenterology, Tangail Medical College, Bangladesh. \\ 2. Associate Professor of Gastroenterology, US-Bangla Medical College, Narayangonj, Bangladesh. \\ 3. Assistant Professor of Gastroenterology, Mymensingh Medical College, Bangladesh \\ 4. Assistant Professor of Gastroenterology, Rangpur Medical College, Bangladesh \\ 5. Medical Officer,Cox's Bazar Medical College, Bangladesh \\ 6. Assist Registrar (Gynae and obs),General Hospital, Narayangonj, Bangladesh \\ 7. Assistant Prof of ENT, Head \& Neck Surgery,US-Bangla Medical College, Narayangonj.
}

DOI: 10.31364/SCIRJ/v7.i7.2019.P0719680

http://dx.doi.org/10.31364/SCIRJ/v7.i7.2019.P0719680

\begin{abstract}
Irritable bowel syndrome (IBS) is a common disorder in our daily clinical practice which is a chronic, relapsing gastrointestinal problem, characterized by abdominal pain, bloating and changes in bowel habit. Symptoms caused by lactose malabsorption may be confused with those of IBS and the two disorders can also co-exist in the same person. The aim of this study was to see the prevalence of lactose intolerance in persons with IBS and also to see the prevalence of lactose intolerance in persons without IBS. This observational study was carried out in the Department of Gastroenterology of BSMMU, Dhaka during July 2010 to September 2011.Total 100 patients fulfilling Rome III criteria for IBS and 30 age and sex matched people without having any symptoms of IBS or organic gastrointestinal disease or systemic disease were enrolled and were advised for lactose tolerance test (LTT). For lactose tolerance test fasting blood glucose level was measured, then 50gm of lactose was given orally and blood glucose was measured after $30 \mathrm{mins}$ of ingestion of lactose. An increase less than $20 \mathrm{mg} / \mathrm{dL}$ over base line after 30 mins. indicate positive lactose intolerance. Lactose intolerance was found 62 (62\%) in IBS and 13 (43.3\%) in control group (p>0.05). Among the lactose intolerance patients, maximum patients were service holder in both group, which was $43.5 \%$ and $53.8 \%$ in IBS and control group respectively. The mean age was $31.47 \pm 8.36$ years in IBS and $37.77 \pm 10.44$ years in control group in patients with lactose Intolerance. Patients with lactose intolerance, the mean blood glucose during fasting was $5.0 \pm 0.49 \mathrm{mmole} / \mathrm{L}$ in IBS and $5.28 \pm 0.56 \mathrm{mmole} / \mathrm{L}$ in control group. After lactose the mean blood glucose was $5.67 \pm 0.49 \mathrm{mmole} / \mathrm{L}$ and $5.97 \pm 0.55$ in IBS and control group respectively. Our recommendation is to perform lactose tolerance test before the diagnosis of IBS. Further large scale study is suggested.
\end{abstract}

Key words: Irritable bowel syndrome (IBS), lactose tolerance test (LTT).

\section{INTRODUCTION}

Irritable bowel syndrome (IBS) is a common disorder worldwide. It is found in $10 \%$ to $20 \%$ of general population using standard diagnostic tools such as the Rome II criteria (Drossman et al. 2000). In Bangladesh the prevalence of IBS was found to be $7.7 \%$ in urban community (Perveen et al. 2009) and the prevalence was found $8.5 \%$ in rural community (Masud, Hasan and Khan 2001). It is a 
chronic, relapsing gastrointestinal problem, characterized by abdominal pain, bloating and changes in bowel habit. IBS is troublesome disorder, with a significant negative impact on quality of life and social functioning in many patients (Andrews et al. 2005, Dean et al. 2005 and Longstreth et al. 2005). Lactose intolerance is the most common manifestation of disaccharidase deficiency (Corrao et al. 2001). Deficiency of the intestinal brush border enzyme lactase lead to lactose malabsorption, which can result in lactose intolerance. Lactose intolerance may be congenital, may be acquired. Acquired lactose intolerance can again be divided into two way such as acquired primary lactase deficiency (adult type hypolactasia) and lactase deficiency induced by underlying intestinal diseases (Feldman et al. 2010). Most of the symptoms of IBS can also occur as a result of lactose malabsorption (Bozanni et al. 1986). So symptoms caused by lactose malabsorption may be confused with those of IBS and the two disordered can also co-exist in the same person. So diagnosis of lactose intolerance should be tried before the diagnosis of IBS is made, at least in patients with milk related symptoms. The recent study has reviewed the results of numerous investigations in more than 1000 IBS patients and found the prevalence of LM to be $23 \%$, virtually the same as what would be expected in the general US populations (Hamm et al. 1999). Therefore a test for LM has been performed before the diagnosis of IBS is made, at least in patients with milk related symptoms (Vernia et al. 2001). However it has been questioned whether LM might mimic IBS (Turubull 2000).

METHODS: This observational study was carried out in the Department of Gastroenterology of BSMMU, Dhaka during July 2010 to September 2011, to see the prevalence of lactose intolerance in persons with irritable bowel syndrome (IBS) (Rome III criteria) and without irritable bowel syndrome (IBS).

For this purpose, a total number of 100 patients of either sex, age 18 years and above fulfilling Rome III criteria for IBS were studied and 30 age and sex matched people without having any symptoms of IBS or organic gastrointestinal disease or systemic disease was studied as control group in this study.

After initial enrollment clinical history was noted in a standard data sheet and they were advised for base line investigations. After final selection of patients they were advised for lactose tolerance test (LTT). For lactose tolerance test fasting blood glucose level was measured, then $50 \mathrm{gm}$ of lactose was given orally and blood glucose was measured after $30 \mathrm{mins}$ of ingestion of lactose. An increase less than $20 \mathrm{mg} / \mathrm{dL}$ over base line after 30 mins. indicate positive lactose intolerance. Statistical Analysis was done using the Statistical package for social science (SPSS version 16). Test of association between lactose intolerance and IBS was carried out by Chi square test and Unpaired t-test.

\section{OBSERVATIONS AND RESULTS}

A total of 130 subjects age belonged to 18 to 60 years of ambulatory patients of both sexes were enrolled in this study, out of which 100 patients fulfilling Rome III criteria for IBS was consider as case and 30 matched people without having any symptoms of IBS or organic gastrointestinal disease or systemic disease was considered as control group. In this current study it was observed that the mean $( \pm \mathrm{SD})$ age was 31.67 years with range from 17 to 51 years and $34.73 \pm 7.55$ years with range from 19 to 52 years in IBS and control respectively. The age distribution between two groups was almost similar, no significant $(\mathrm{p}>0.05)$ difference was found between two groups. Maximum number was found in the $3^{\text {rd }}$ decade in both groups. In this present study male was found $84.0 \%$ in IBS and $73.3 \%$ in control group and male female ratio was 4:1 in the whole study subjects ( Table-I ).

Table I: Age distribution of the study patients $(n=130)$

\begin{tabular}{lccccc}
\hline \multirow{2}{*}{ Age (in year) } & \multicolumn{2}{c}{$\begin{array}{c}\text { IBS } \\
(\mathbf{n = 1 0 0})\end{array}$} & \multicolumn{2}{c}{$\begin{array}{c}\text { Control } \\
(\mathbf{n}=\mathbf{3 0})\end{array}$} & \multirow{2}{*}{ P value } \\
\cline { 2 - 5 } & $\mathrm{n}$ & $\%$ & $\mathrm{n}$ & $\%$ & \\
\hline$\leq 20$ & 6 & 6.0 & 2 & 6.7 \\
$21-30$ & 48 & 48.0 & 11 & 36.7 \\
$31-40$ & 30 & 30.0 & 10 & 33.3 \\
$41-50$ & 15 & 15.0 & 6 & 20.0 & \\
$>50$ & 1 & 1.0 & 1 & 3.3 & \\
\hline Mean \pm SD & \multicolumn{2}{c}{$31.67 \pm 8.59$} & \multicolumn{2}{c}{$34.73 \pm 7.55$} & \multirow{2}{*}{$0.081^{\mathrm{ns}}$} \\
Range (min-max) & \multicolumn{2}{c}{$(17-51)$} & \multicolumn{2}{c}{$(19-52)$} & \\
\hline
\end{tabular}

Regarding the occupational status it was found in this current series that most of the patients were service holder in both groups, which were $40.0 \%$ in IBS and $63.3 \%$ in control group. Housewife was found $11.0 \%$ in IBS and $10.0 \%$ in control group. In this series it was observed that lactose intolerance was higher in patients with irritable bowel syndrome (IBS), which was $62.0 \%$ in IBS and $43.3 \%$ in control, that was not statistically significant ( $p>0.05)$ between two groups. A total of 62 in IBS and 13 in control groups having lactose intolerance in this present series(Table II and III). Lactose intolerance found $83.9 \%$ in IBS and $76.9 \%$ in control in 
male patient. Female was found $16.1 \%$ and $23.1 \%$ in IBS and control group respectively, which was not statistically significant $(\mathrm{p}>0.05)$ between two group.

Table II: Distribution of lactose intolerance in IBS patients $(\mathbf{n}=100)$

\begin{tabular}{lcc}
\hline Lactose intolerance & Number of patients & Percentage \\
\hline Present & 62 & 62.0 \\
Absent & 38 & 38.0 \\
\hline
\end{tabular}

Table III: Distribution of lactose intolerance in control group $(n=30)$

\begin{tabular}{lcc}
\hline Lactose intolerance & Number of patients & Percentage \\
\hline Present & 13 & 43.3 \\
Absent & 17 & 56.7 \\
\hline
\end{tabular}

In this study it was observed in the lactose intolerance patients most of them were service holder in both group (43.5\% vs. $53.8 \%$ ) and female patients were mostly housewife, which were $11.3 \%$ and $15.4 \%$ in IBS and control respectively .

In this current study it was observed that the mean age was $31.47 \pm 8.36$ years in IBS and $37.77 \pm 10.44$ years in control group in patients with lactose Intolerance. The mean age was significantly ( $p>0.05)$ younger in IBS group in patients having lactose

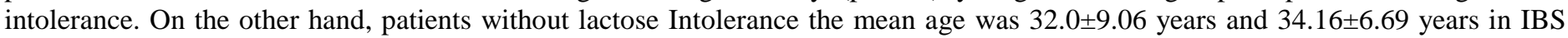
and control group respectively, which was almost similar between two groups not statistically significant ( $\mathrm{p}>0.05)$ difference was found between two groups in patients without lactose intolerance(Table IV).

Table IV: Mean age distribution according to lactose intolerance present or absent in both groups (n=130).

\begin{tabular}{lccc}
\hline Age in years & $\begin{array}{c}\text { IBS } \\
(\mathbf{n = 1 0 0})\end{array}$ & $\begin{array}{c}\text { Control } \\
(\mathbf{n = 3 0})\end{array}$ & $\begin{array}{c}\text { P } \\
\text { Value }\end{array}$ \\
\cline { 2 - 3 } & Mean+SD & Mean+SD & \\
\hline Lactose intolerance (present) & $31.47 \pm 8.36$ & $37.77 \pm 10.44$ & $0.021^{\mathrm{s}}$ \\
$\quad$ Range (min-max) & $(18-50)$ & $(22-52)$ & \\
Lactose intolerance (absent) & $32.0 \pm 9.06$ & $34.18 \pm 6.69$ & $0.371^{\mathrm{ns}}$ \\
$\quad$ Range (min-max) & $(17-51)$ & $(25-45)$ & \\
\hline
\end{tabular}

Patients with lactose intolerance it was observed in this present study that the mean blood glucose during fasting was $5.0 \pm 0.49$ $\mathrm{mmole} / \mathrm{L}$ in IBS and $5.28 \pm 0.56 \mathrm{mmole} / \mathrm{L}$ in control group. After lactose the mean blood glucose was $5.67 \pm 0.49 \mathrm{mmole} / \mathrm{L}$ and $5.97 \pm 0.55$ in IBS and control group respectively. On the other hand, patients without lactose intolerance the mean blood glucose during fasting was $4.87 \pm 0.49 \mathrm{mmole} / \mathrm{L}$ in IBS and $4.82 \pm 0.37 \mathrm{mmole} / \mathrm{L}$ in control group. Similarly, after lactose the mean blood glucose was $6.33 \pm 0.58 \mathrm{mmole} / \mathrm{L}$ and $6.32 \pm 0.42 \mathrm{mmole} / \mathrm{L}$ in IBS and control group respectively. The mean difference was not statistically significant $(\mathrm{p}>0.05)$ in patients with lactose intolerance and patients without lactose intolerance between two groups(Table V).

Table V: Mean blood sugar during fasting and after lactose in the lactose intolerance present or absent in both groups $(n=130)$.

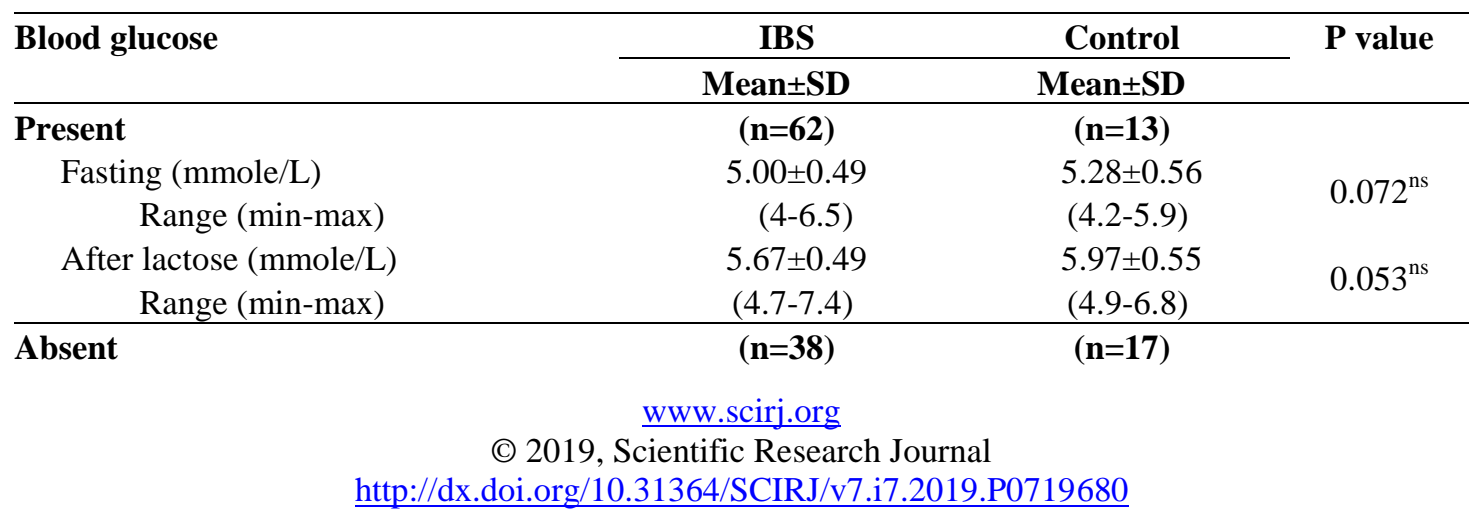




\begin{tabular}{cccc} 
Fasting (mmole/L) & $4.87 \pm 0.49$ & $4.82 \pm 0.37$ & $0.709^{\mathrm{ns}}$ \\
Range (min-max) & $(4-5.9)$ & $(4.2-5.4)$ & \\
After lactose (mmole/L) & $6.33 \pm 0.58$ & $6.32 \pm 0.42$ & $0.949^{\mathrm{ns}}$ \\
Range (min-max) & $(5.1-7.4)$ & $(5.6-6.9)$ & \\
\hline
\end{tabular}

\section{DISCUSSION}

Irritable bowel syndrome is common in our country. In Bangladesh the prevalence of IBS was found to be $7.7 \%$ in urban community (Perveen et al. 2009) and the prevalence was found 8.5\% in rural community (Masud, Hasan and Khan 2001). Lactose intolerance is also common in our country.

In this current study it was observed that the mean $( \pm \mathrm{SD})$ age was 31.67 years with range from 17 to 51 years and $34.73 \pm 7.55$ years with range from 19 to 52 years in IBS and control respectively. The age distribution between two groups was almost similar, no significant $(\mathrm{p}>0.05)$ difference was found between two groups. Maximum number was found in the $3^{\text {rd }}$ decade in both groups. Similarly, Gupta et al. (2007) found the mean age was $35.5 \pm 11.1$ years in IBS and 33.5 \pm 9.1 years in controls. Corrao et al. (2001) showed the mean age at diagnosis was $35.7 \pm 14.1$ years in their study patients. In another study, Vernia et al. (2001) showed the mean age was $36.2 \pm 13.9$ years and $37.8 \pm 13.9$ years in patients with IBS in male and female respectively. In milk intolerance patients the mean age was $32.1 \pm 13.5$ years in male and $36.1 \pm 14.8$ years in female. The above findings regarding the mean age are comparable with the current study. On the other hand, Dean et al. (2005) found higher mean age in their study patients that was $40.6 \pm 10.5$ years in IBS and $41.4 \pm 11.2$ years without IBS. Similar higher mean age obtained by Nanda et al. (1998), where the investigators found the mean age was $43.87 \pm 14.5$ years in IBS and $42.91 \pm 16.7$ years in control group. In another study, Farup et al. (2004) reported the mean age in their study patients were 48.8 years and 46.3 years in IBS and control respectively. Hamm et al. (1999) showed the mean age of

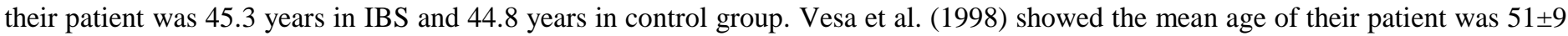
years in IBS and $50 \pm 9$ years in no IBS, which are higher with the present study, this may be due to increased life expectancy and geographical location.

In this present study male was found $84.0 \%$ in IBS and $73.3 \%$ in control group and male female ratio was $4: 1$ in the whole study subjects. Gupta et al. (2007) found male $73.0 \%$ and $72.0 \%$ in IBS and control respectively, which is consistent with the present study. Vesa et al. (1998), Dean et al. (2005), Andrews et al. (2005), Farup et al. (2004), Monsbakken and Vandvik (2004), Hamm et al. (1999), Corrao et al. (2001) found female predominant in their study. Simrén et al. (2001) reported in their study that female sex and anxiety predict a high degree of food-related symptoms in IBS, which differ with the current study, this may be due to the current study patient were included from the out patients department.

Regarding the occupational status it was found in this current series that most of the patients were service holder in both groups, which were $40.0 \%$ in IBS and $63.3 \%$ in control group. Housewife was found $11.0 \%$ in IBS and $10.0 \%$ in control group.

In this series it was observed that lactose intolerance was higher in patients with irritable bowel syndrome (IBS), which was $62.0 \%$ in IBS and $43.3 \%$ in control, that was not statistically significant ( $p>0.05)$ between two groups. Bourlioux and Pochart (1988) and Scrimshaw and Murray (1988) reported in their study that the incidence of lactose malabsorption is estimated to be $25.0 \%$ in the U.S. and as much as $75.0 \%$ worldwide. The incidence of lactose malabsorption $23.0 \%$ seen by Hamm et al. (1999). In out country, Maksudul et al. (1996) and Shamim et al. (2006) showed the prevalence of lactose intolerance $67.5 \%$ and $68.0 \%$ respectively in patient having IBS, which is comparable to that expected in the general population.

The high frequency of LI in patients with irritable bowel syndrome (IBS) and in HS is in accordance with previous reports that show LI to be common in India (Rana et al. 2001) in contrast to developed countries. Matthews et al. (2005) and Romagnuolo et al. (2002) documented in their study that this may be related to differences in genetic, ethnic and geographic background all of which are known to influence the frequency of LI in a population. Genetic bases for differences in loss of lactase activity with increasing age have been reported.

Farup et al. (2004) showed lactose malabsorption $4.1 \%$ in irritable bowel syndrome (IBS) and health volunteers $3.8 \%(P>0.05)$. Vernia et al. (2001) mentioned that the lactose HBT was positive in $66.9 \%$ irritable bowel syndrome (IBS) patients, while $4.6 \%$ patients were classified as hydrogen non-producers.

A total of 62 in IBS and 13 in control groups having lactose intolerance in this present series. Lactose intolerance found $83.9 \%$ in IBS and $76.9 \%$ in control in male patient. Female was found $16.1 \%$ and $23.1 \%$ in IBS and control group respectively, which was not statistically significant ( $>0.05)$ between two group. Vesa et al. (1998) showed female sex increased the risk of subjective lactose intolerance, where OR=2.1 with 95\% CI (1.1-4.5). Parker et al. (2000) showed positive $24.0 \%$ in male and $76.0 \%$ female. In the same study, the authors had done a lactose hydrogen breath test, performed on 122 irritable bowel syndrome (IBS) patients, was positive in $27.0 \%$ and negative in $73.0 \%$. The proportion of men to women and was not significantly different in those having a positive or negative LHBT $(P>0.05)$.

In this current study it was observed that the mean age was $31.47 \pm 8.36$ years in IBS and $37.77 \pm 10.44$ years in control group in patients with lactose Intolerance. Parker et al. (2000) have shown the age distribution not significantly different in those having a positive or negative LHBT $(P>0.05)$.

Patients with lactose intolerance it was observed in this present study that the mean blood glucose during fasting was 5.0 \pm 0.49 mmole/L in IBS and $5.28 \pm 0.56 \mathrm{mmole} / \mathrm{L}$ in control group. After lactose the mean blood glucose was $5.67 \pm 0.49 \mathrm{mmole} / \mathrm{L}$ and 
$5.97 \pm 0.55$ in IBS and control group respectively. On the other hand, patients without lactose intolerance the mean blood glucose during fasting was $4.87 \pm 0.49 \mathrm{mmole} / \mathrm{L}$ in IBS and $4.82 \pm 0.37 \mathrm{mmole} / \mathrm{L}$ in control group. Similarly, after lactose the mean blood glucose was $6.33 \pm 0.58 \mathrm{mmole} / \mathrm{L}$ and $6.32 \pm 0.42 \mathrm{mmole} / \mathrm{L}$ in IBS and control group respectively. The mean difference was not statistically significant $(\mathrm{p}>0.05)$ in patients with lactose intolerance and patients without lactose intolerance between two groups.

Conclusion: This observational study was carried out with an aim to establish the prevalence of lactose intolerance in persons with IBS (Rome III criteria) and without IBS. The study showed lactose intolerance is common both in IBS (62.0\%) and in control group $(43.3 \%)$. The results of the present study showed that age, sex, lactose intolerance were almost comparable in both groups, however lactose intolerance was higher in patients with irritable bowel syndrome (IBS) but is comparable.

\section{References :}

1. Andrews EB, Eaton SC, Hollis KA, Hopkins JS, Ameen V, Hamm LR et al. 2005, 'Prevalence and demographics of irritable bowel syndrome: results from a large web-based survey’, Aliment Pharmacol Ther, 22, p. 935-942.

2. Arya S 1998, 'Rotavirus infection and intestinal lactase level', J Infect Dis, 150, p. 791.

3. Bourlioux P, Pochart P, 1988, 'Nutritional and health properties of yogurt', World Rev Nutr Diet, 56, p. $217-58$.

4. Bozzani A, Penagini R, Velio P, Camboni G, Corbellini A, Quatrini M. et al. 1986, 'Lactose malabsorption and intolerance in Italians. Clinical implications', Dig Dis Sci, 31(12), p.1313-6.

5. Caspary WF 1986, 'Diarrhea associated with carbohydrate malabsorption', Clin Gastroenterol, 15, p.631-34.

6. Corrao G, Corazza GR, Bagnardi V, Brusco G, Ciacci C, Cottone M et al. 2001, 'Mortality in patients with coeliac disease and their relatives: a cohort study', Lancet, 358, p. 356-61.

7. Dean BB, Aguilar D, Barghout V 2005, 'Impairment in work productivity and health-related quality of life in patients with IBS', Am J Manag Care, 11, p. 17-26.

8. Drossman DA, Corazziari E, Talley NJ, Thompson WG, Whitehead WE 2000. editors. Rome II. The functional gastrointestinal disorders: Diagnosis, pathophysiology and treatment: A Multinational consensus. 2nd ed. McLean, Va: Degnon and Associates.

9. Drossman DA, 2003, 'The “organification” of functional GI disorders: implications for research', Gastroenterology, 124, p. $6-7$.

10. Enattah N, Sahi T, Savilahti E et al. 2002, 'Identification of a variant associated with adult-type hypolactasia', Nat. Genet, 30, p.233-7.

11. Farup PG, Monsbakken KW, Vandvik PO 2004, 'Lactose malabsorption in a population with irritable bowel syndrome: Prevalence and symptoms. A case control study', Scand J Gastroenterol, 39, p. 645-649.

12. Feldman M, Friedman LS, Brant LJ, 2010, 'Sleisenger and Fordtrean's', 1, p. 1754-1755.

13. Ferguson A, Macdonald DM AND Brydon WG 1984, 'Prevalence of lactase deficiency in British adults', Gut, 25, p. 163167.

14. Gupta D, Ghoshal UC, Misra A, Misra A, Choudhuri G AND Singh K 2007, 'Lactose intolerance in patients with irritable bowel syndrome from northern India: A case-control study', Journal of Gastroenterology and Hepatology, 22, p 2261-2265.

15. Hamm LR, Sorrells SC, Harding JP 1999, 'Additional investigations fail to after the diagnosis irritable bowel syndrome in subjects fulfilling the Rome criteria', Am J Gastroenterol, 94, p. 1279-1282. 
16. Hyms J, Krause P, Gleason P, 1981, 'Lactose malabsorption following rotavirus infection in young children', J Pediatr, 99, p. $916-18$.

17. Joseph F, Rosenberg AJ 1986, 'Identifying lactose malabsorbers through breath hydrogen measurements', Lab Med, 17, p. 85.

18. Kalantar JS, Locke III GR, Zinsmeister AR 2003, 'Psychosocial factors are linked to functional gastrointestinal disorders: a population based nested case-control study', Am J Gastroenterol, 99, p.350-7.

19. Kruis W, Thieme C, Weinzierl M et al. 1984, 'A diagnostic score for the irritable bowel syndrome. Its value in the exclusion of organic disease', Gastroenterology, 87, p. 1-7.

20. Lembo A, Zaman M, Jones M 2007, 'Influence of genetics on irritable bowel syndrome, gastro-oesophageal reflux and dyspepsia: a twin study', Aliment Pharmacol Ther, 25, p.1343-50.

21. Locke GR, Weaver AL, Melton III LJ 2004, 'Familial aggregation of irritable bowel syndrome: a prospective study', Gut, 52, p. 1703-7.

22. Madden JA, Hunter JO 2002, 'A review of the role of the gut microflora in irritable bowel syndrome and the effects of probiotics', Br J Nutr, 88, p. S67-72.

23. Manning AP, Thompson WG, Heaton KW, Morris AF 1978, 'Towards positive diagnosis of the irritable bowel', BMJ, 2, p. 653-4.

24. Masud MA, Hasan M, Khan AK 2001, 'Irritable bowel syndrome in a rural community in Bangladesh: prevalence, symptoms pattern, and health care seeking behavior', Am J Gastroenterol, 96(5), p.1547-52.

25. Matthews S, Waud J, Roberts A, Campbell A 2005, 'Systemic lactose intolerance: a new perspective on an old problem', Postgrad. Med. J, 81, p. 167-73.

26. Mearin F, Baro E, Roset M 2004, 'Clinical patterns over time in irritable bowel syndrome: symptom instability and severity variability’, Am J Gastroenterol, 99, p. 113-21. 